\title{
Tratamiento primario de aguas servidas mediante tanque séptico en urbanización de Lurigancho, Lima
}

\section{PRIMARY TREATMENT OF SEWAGE BY SEPTIC TANK IN THE URBANIZATION OF LURIGANCHO, LIMA}

\author{
SARITA AGUIRRE SOLIS§, MIQUEAS VARGAS URBANO§, MIGUMI ZERON CANCHA§, \\ MILDA CRUZ HUARANGA§*, STIVE FLORES-GÓMEZ
}

Recibido: 15 septiembre de 2018 / Aceptado: 07 noviembre de 2018

§EP. Ingeniería Ambiental, Facultad de Ingeniería y Arquitectura, Universidad Peruana Unión, Perú.

\section{Resumen}

Un problema latente en el mundo, cuya resolución aún viene siendo estudiada es el tratamiento y disposición final de los residuos líquidos provenientes del uso doméstico, comercial o industrial. En zonas rurales o urbanas que no poseen un sistema de alcantarillado, o en zonas que por la distancia no justifica su instalación, una alternativa de tratamiento primario es el empleo del sistema de tanque séptico, que es un depósito cerrado (rectangular o circular) donde las aguas servidas son fermentadas de manera anaerobia de uno a tres días, resultado de ello la disposición de agua, gas metano, bióxido de carbono y lodos, productos que podrían tener múltiples usos. El proyecto piloto se ejecutó a escala real empleando un tanque séptico y se realizó en una vivienda familiar del distrito de Lurigancho-Chosica (Lima). El objetivo de este trabajo fue mejorar la calidad del agua, considerando los parámetros fisicoquímicos (sólidos suspendidos totales, turbiedad, $\mathrm{pH}$, oxígeno disuelto, conductividad, $\mathrm{DBO}_{5}$, y biológicos (coliformes totales y fecales). Para la construcción del tanque séptico se realizó la excavación en un área de $0.88 \mathrm{~m}^{2}$ con una profundidad de 1.7 m; para la construcción de las paredes y las cámaras se utilizaron ladrillos y mezcla de cemento y arena fina, además para la conexión de las tuberías provenientes de la cocina y servicios, se utilizaron tuberías de 2 " y 4" de diámetro. El tanque se recubrió con una capa de plástico y una plancha de tecnopor (1.05 x 0.75 $\mathrm{m}$ ), como medida de seguridad se elaboró una tapa de madera. Los parámetros físicoquímicos y biológicos se analizaron en laboratorio. Se concluye que el prototipo a escala real del tanque séptico, tiene una eficiencia de $63.12 \%$ de funcionamiento con un proceso de retención de 3 días, un caudal de 4.624x106 $\mathrm{m}^{3} / \mathrm{s}$ y un volumen depositado de $0.216 \mathrm{~m}^{3}$.

Palabras claves: contaminación, calidad del agua, residuos líquidos.

\begin{abstract}
A latent problem in the world, whose resolution is still being studied is the treatment and final disposal of liquid waste from domestic, commercial or industrial use. In rural or urban areas that do not have a sewerage system, or in areas that do not justify the installation, a primary treatment alternative is the use of the septic tank system, which is a closed tank (rectangular or circular) where wastewater is fermented anaerobically from one to three days, resulting in the disposal of water, methane gas, carbon dioxide and sludge, products that could have multiple uses. The pilot project was implemented on a real scale using a septic tank and was carried out in a family home in the district of Lurigancho-Chosica (Lima). The objective of this work was to improve water quality, considering the physicochemical parameters (total suspended solids, turbidity, $\mathrm{pH}$, dissolved oxygen, conductivity, $\mathrm{BOD} 5$, and biological (total and fecal coliforms). excavation in an area of $0.88 \mathrm{~m}^{2}$ with a depth of $1.7 \mathrm{~m}$, for the construction of walls and chambers were used bricks and cement mixture and fine sand, in addition to the connection of the pipes from the kitchen and services, were used 2" and 4" diameter pipes. The tank was covered with a plastic layer and a technopor plate $(1.05 \times 0.75 \mathrm{~m})$, as a safety measure, a wooden lid was prepared. The physicochemical and biological parameters were analyzed in It is concluded that the full-scale prototype of the septic tank has an efficiency of $63.12 \%$ of operation with a retention process of 3 days, a flow of $4.624 \times 106 \mathrm{~m}^{3} / \mathrm{s}$ and a deposited volume of $0.216 \mathrm{~m}^{3}$.
\end{abstract}


Key words: pollution, water quality, liquid waste.

\section{INTRODUCCIÓN}

Un problema latente en el mundo y cuya resolución viene siendo analizada es el tratamiento y disposición final de los residuos líquidos provenientes del uso doméstico, comercial o industrial. Los cuerpos receptores de estas aguas, principalmente ríos, corrientes subterráneas, lagos, estuarios y mar, son comúnmente afectadas por la contaminación, y pierden sus condiciones naturales de apariencia física, química y biológica y por ende su equilibrio ecológico (Larios-Meoño et al, 2015).

Las aguas residuales sin tratamiento constituyen un peligro para la salud pública y de los ecosistemas acuáticos, dado a la incorporación de alta carga de materia orgánica, que provoca eutrofización y posteriormente anoxia en el agua y torna difícil la recuperación de las comunidades acuáticas, su impacto tiene repercusiones sociales, económicos y ambientales (Rodríguez et al. 2016).

En localidades que no disponen alcantarillado municipal, la disposición de excretas y aguas residuales hacen vulnerable a la salud pública, puesto que su mal manejo puede favorecer el desarrollo de enfermedades como la tifoidea, disentería, cólera y las vinculadas con el parasitismo se trasmite a través del agua, vectores, suelo y alimentos contaminados (OMS, 2015)

El empleo de tanque séptico se convierte en una buena alternativa como sistema de tratamiento primario y disposición de efluentes domésticos dado a que posibilita la sedimentación de sólidos, en el proceso, los sólidos orgánicos se descomponen por acción bacteriana anaerobia. Dicho sistema podría ser implementado en zonas rurales o urbanas que carecen de tratamiento de aguas residuales, o se encuentran tan alejadas como para justificar su instalación. Esta agua tratada sirve para regadíos, lavado de autos o pasar a otro tratamiento.

El tanque séptico es un sistema de tratamiento descentralizado más común a pequeña escala para aguas grises y aguas negras, cumple la función de sedimentación (Astavisa, 2015). Los tanques sépticos se construyen generalmente de concreto, fibra de vidrio, polietileno, ferrocemento, plástico y de bloques de concreto, y están disponibles como unidades prefabricadas. Los tanques de fibra de vidrio y de plástico son ligeros y de uso frecuente en los sitios donde se dificulta el transporte de los tanques de concreto. Estos sistemas generalmente están diseñados para tratar el agua residual durante un tiempo mínimo de 36 a 72 horas (Lucho-Constantino et al., 2015)

Según la Organización Panamericana de la Salud (2015) el sistema de tanques sépticos es utilizable en localidades rurales, urbanas y urbano-marginales. El objetivo de su diseño es crear una situación de estabilidad hidráulica, que permita la sedimentación por gravedad. Los sólidos sedimentables forman una capa de lodo en el fondo del tanque séptico.

\section{MATERIALES Y MÉTODOS}

\section{LUGAR DE ESTUDIO}

La investigación se efectuó en una propiedad privada ubicada en una urbanización de Carapongo, Lurigacho (Lima), zona que está localizada al margen este de la ciudad de 
Lima (Figura 1).

La construcción del tanque séptico se realizó en una vivienda familiar. Sus coordenadas geográficas (UTM) son 297562 LE y 8673174 LS.

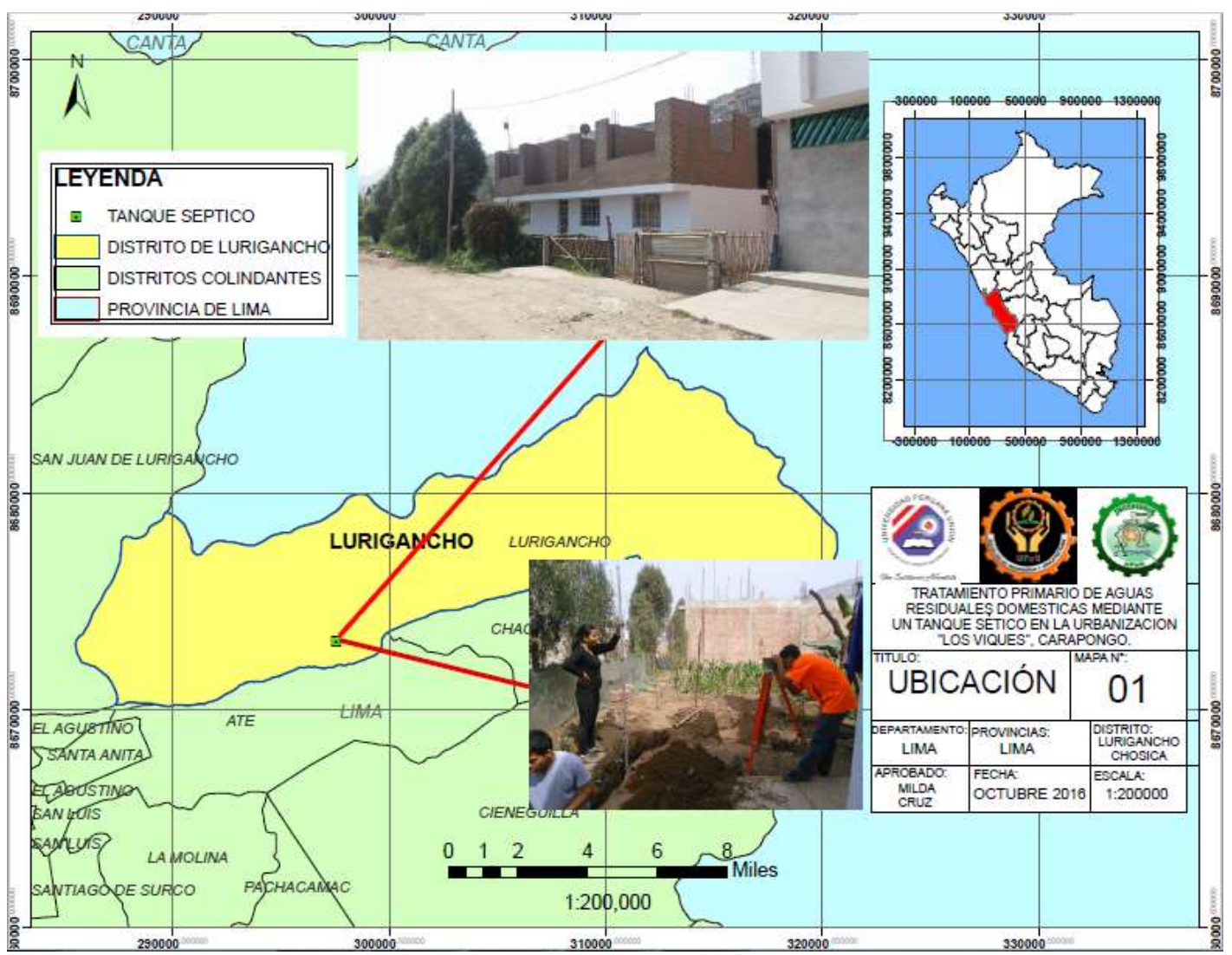

Figura 1. Mapa de ubicación de la zona de estudio

\section{CONSIDERACIONES TÉCNICAS}

\section{Diseño de tanque séptico}

Según la norma técnica peruana I.S. 0.20 tanques sépticos y especificaciones técnicas para la construcción de tanque séptico, tanque Imhoff y laguna de estabilización de la Organización Panamericana de la salud y Organización Mundial de la salud, (OPS/OMS, 2005). El diseño del tanque séptico considera los siguientes aspectos:

a) Tamaño del tanque séptico

- Depende del número de recamaras de la casa.

- El número de personas que viven en la casa.

- Si se usa o no aparatos del baño o de la cocina que ahorren agua.

b) Construcción del Tanque Séptico

- Un factor clave en el diseña del tanque séptico es la relación entre cuanta área de superficie tiene, cuánta agua residual puede guardas, cuánta agua residual se vierte y que tan rápido sale. 
Para la obtención de los cálculos se necesitara la norma técnica peruana, los siguientes capitulo:

Tiempo de retención:

Donde:

$$
P R=1.5-0.3 * \log (P . q)
$$

$\mathrm{PR}=$ tiempo de retención hidráulica, en días

$\mathrm{P}=$ población servida

$\mathrm{q}=$ caudal de aporte unitario de aguas residuales, Lt/ habitante día

El tiempo mínimo de retención hidráulico será de 6 días

Volumen de Tanque Séptico:

a) El volumen requerido para el sedimento $\mathrm{Vs}$ en $\mathrm{m} 3$ se calcula mediante la fórmula:

$$
V_{s}=10^{-3} *(P q) * P R
$$

b) Se debe considerar un volumen de digestión y almacenamiento de lodos $\left(\mathrm{Vd}\right.$, en $\left.\mathrm{m}^{3}\right)$ basado en un requerimiento anual de 70 litros por persona que se calculará mediante la fórmula:

$$
V_{d}=70 * 10^{-3} * P N
$$

$\mathrm{N}=$ es el intervalo deseado, en años, entre operaciones sucesivas de remoción de lodos. El tiempo mínimo de remoción de lodos es de 1 año.

Dimensiones:

a) Profundidad máxima de espuma sumergida $\left(\mathrm{H}_{\mathrm{e}}\right.$, en $\left.\mathrm{m}\right)$

b) Debe existir una profundidad mínima aceptable de la zona de sedimentación.

c) La profundidad libre lodo es distancia entre la parte superior de la capa de lodo y el nivel de la Tee

$$
\begin{gathered}
H_{e}=\frac{0.7}{A} \\
H_{O}=0.82-0.26 * A
\end{gathered}
$$

Materiales: concreto y ladrillo

Accesorios: Todos tanque séptico tendrá losas removibles, de limpieza y registros de inspección. Las osas removibles deberá estar colocadas principalmente sobre los dispositivos de entrada y salida.

Dispositivos de entrada y salida: el diámetro de las tuberías de entrada y salida de los tanque sépticos será de $100 \mathrm{~mm}$.

Muro o tabique divisorio: cuando el tanque tengamos de una cámara se deberá proveer abertura por nivel de arriba de la nata y por debajo del lodo

Fondo del tanque séptico: El fondo del tanque séptico tendrá una pendiente de $2 \%$ orientada hacia el punto de ingreso de los líquidos. 


\section{Funcionamiento del tanque séptico}

Las aguas residuales doméstica, provenientes de cocinas, duchas y baños, son encaminadas mediante tuberías al sistema del tanque séptico. El tanque séptico tiene dos unidades o zonas, en la primera unidad llegan toda las aguas residuales, donde se da una situación de estabilidad hidráulica, que permite la sedimentación por gravedad de las partículas pesadas que van al fondo y las partículas livianas y las grasas se acumulan en la parte superior (etapa de sedimentación). Pero se tiene que hacer un tiempo de retención durante un tiempo mínimo es 6 horas mínimas y 72 horas máximas. Donde los sólidos sedimentables que se encuentren en el agua residual cruda formando una capa de lodo en el fondo del sistema.

En esta misma unidad se da la etapa biológica de tratamiento por bacterias anaerobias. Este mecanismo es importante para la remoción de la materia orgánica presente en el agua residual; el metabolismo bacteriano consiste en la utilización de la materia orgánica como fuente de energía y carbono para generar nueva biomasa.

\section{Digestión anaerobia}

Rodríguez (2011) menciona que la digestión Anaerobia es el proceso fermentativo que ocurre en el tratamiento anaerobio de las aguas residuales. El proceso se caracteriza por la conversión de la materia orgánica a metano, $\mathrm{CO}_{2}$ y a una suspensión acuosa o lodo, en ausencia de oxígeno y con la interacción de diferentes poblaciones bacterianas. La digestión consiste en dos:

a) El catabolismo, se divide en dos procesos fundamentalmente diferentes: (1) Catabolismo Oxidativo, es una reacción redox, donde la materia orgánica es el reductor que es oxidada por un oxidante (el oxígeno, nitrato o sulfato). (2) Catabolismo Fermentativo, se caracteriza por el hecho de no haber presencia de un oxidante, el proceso resulta en un reordenamiento de los electrones de la molécula fermentada de un modo tal que se forman como mínimo dos productos $\mathrm{CH}_{4} \mathrm{y} \mathrm{CO}_{2}$.

b) Anabolismo: se produce la síntesis de moléculas a partir simples. El anabolismo es un proceso que consume energía y solamente es viable si el catabolismo está ocurriendo para proporcionarle la energía necesaria para la síntesis celular.

\section{El Tratamiento Anaerobio}

La digestión anaerobia es un proceso de transformación y no de destrucción de la materia orgánica, debido a que no existe la presencia de un oxidante en el proceso, la capacidad de transferencia de electrones de la materia orgánica permanece intacta en el metano producido. En vista de que no hay oxidación, se tiene que la DQO teórica del metano equivale a la mayor parte de la DQO de la materia orgánica digerida (90 a 97\%), una mínima parte de la DQO es convertida en lodo (3 a 10\%). En las reacciones bioquímicas que ocurren en la digestión anaerobia, solo una pequeña parte de la energía libre es liberada, mientras que la mayor parte de esa energía permanece como energía química en el metano producido.

\section{Degradación anaerobia de la materia orgánica}

La degradación anaerobia de la materia orgánica requiere la intervención de diversos grupos de bacterias facultativas (viven con o $\sin \mathrm{O}_{2}$ ) y anaerobias estrictas $\left(\sin \mathrm{O}_{2}\right)$, las cuales utilizan en forma secuencial los productos metabólicos generados por cada grupo. 
La digestión anaerobia de la materia orgánica involucra cuatro pasos de transformación:

Hidrólisis o liquefacción. En esta etapa los compuestos orgánicos son solubilizados por enzimas excretadas por bacterias hidrolíticas que actúan en el exterior celular por lo que se consideran exoenzimas. La hidrólisis es, por tanto, la conversión de los polímeros en sus respectivos monómeros.

Acidogénesis. En esta etapa los compuestos orgánicos solubles que comprenden los productos de la hidrólisis son convertidos en ácidos orgánicos tales como acético, propiónico y butírico, fundamentalmente.

Acetogénesis. Se le conoce también como acidogénesis intermediaria en la cual los productos correspondientes son convertidos en ácido acético, hidrógeno y $\mathrm{CO}_{2}$.

Metanogénesis. En esta etapa metabólica el $\mathrm{CH}_{4}$ es producido a partir del ácido acético o de mezclas de $\mathrm{H}_{2}$ y $\mathrm{CO}_{2}$, pudiendo formarse también a partir de otros sustratos tales como ácido fórmico y metanol. El rol de las bacterias metanogénicas se define por el tipo de sustrato disponible.

Durante la acidificación la disminución de la DBO es mínima Y en la metanogénesis es donde ocurren las mayores disminuciones de la DBO. Cuando existe una cantidad apreciable de sulfatos se desarrollan con intensidad las bacterias formadoras de sulfuro de hidrógeno $\left(\mathrm{H}_{2} \mathrm{~S}\right)$, comúnmente llamadas sulfobacterias.

La digestión anaerobia microbiana da lugar a una mezcla de gaseosa de metano (50 a 70 $\%$ ) y dióxido de carbono (30 a $50 \%$ ), con pequeñas proporciones de otros componentes (nitrógeno, oxígeno, hidrógeno, sulfuro de hidrógeno) y a una suspensión acuosa o "lodo". Por otra parte el da un líquido con mínima cantidad solidos el pasa por un tubo a la segunda unidad. En este lugar también existe una etapa de sedimentación de las materias orgánicas que no sedimentaron en la primera unidad. Finalmente sale por un tubo un líquido libre materia orgánica y grasa. Esta agua se da un tratamiento de filtración luego puede utilizarse para riego o lavado de autos.

Antes de la ejecución del proyecto piloto a escala real de un tanque séptico, se realizó la verificación de la disponibilidad de terreno, características e instalaciones de descarga de sus efluentes domésticos con la autorización del propietario (Ing. Jaulis), los cuales pasamos de describir:

- La familia está integrada por cuatro individuos (papá, mamá e hijos).

- La vivienda vierte sus aguas residuales domésticas a un pozo improvisado de un $1 \mathrm{~m}$ de profundidad, con un diámetro de $0.8 \mathrm{~m}$, que estaba ubicado en la parte posterior de la vivienda y que a su vez está cerca de una canaleta de agua.

- El efluente no recibía ningún tipo de tratamiento tecnificado, ya que solo se filtraba por la capa freática de suelo, además emitía olores desagradables, y existía presencia de moscas.

\section{Foro del caudal}

Para determinar el caudal se utilizó el método, como datos Volumen inicial: $1 \mathrm{~m}^{3}$

Tiempo: $48 \mathrm{~h}$ 


$$
\begin{gathered}
Q=\frac{\text { volumen }}{\text { tiempo }} \\
Q=\frac{1}{48 * 3600} \\
Q=5.78 \times 10^{-6} * 0.8 \\
Q=4.624 X 10^{-6}
\end{gathered}
$$

Resultado se obtuvo un caudal de $4.624 \times 10^{-6} \mathrm{~m}^{3} / \mathrm{s}$.

Análisis de los parámetros fisicoquímicos y organolépticos

El muestreo consistió en:

- En un frasco de plástico de $250 \mathrm{ml}$ esterilizado se tomó una muestra de agua residual doméstica, para el respectivo análisis fisicoquímico

- Para el análisis del parámetro Demanda Química de Oxigeno (DQO) se utilizó un frasco de plástico debidamente esterilizado de $250 \mathrm{ml}$. Y para los parámetros microbiológicos (Coliformes fecales y totales) la muestra de agua residual doméstica fue tomada en un frasco de vidrio de $250 \mathrm{ml}$.

- Una vez que se terminó de realizar el muestreo de los parámetros microbiológicos, los frascos fueron guardados en el culer para ser enviados al Laboratorio de Ecología Microbiana y Biotecnología "Marino Tabusso"- Universidad Agraria de la Molina para su respectivo análisis.

- Los parámetros fiscos (temperatura, conductividad, oxígeno disuelto, solidos totales disueltos, $\mathrm{pH}$ y turbidez) fueron analizados en el Laboratorio de Ingeniería Ambiental perteneciente a la Facultad de Ingeniería y Arquitectura de la Universidad Peruana Unión, Lima.

El análisis consistió en:

a) Para medir la conductividad, sólidos totales disueltos, temperatura; se colocó una muestra de agua residual doméstica en un vaso precipitado de $100 \mathrm{ml}$ y luego se utilizó el equipo multiparámetro HANNA, y automáticamente arrojó los resultado requeridos de cada parámetro solicitado en sus unidades respectivas.

b) En otro vaso precipitado de $100 \mathrm{ml}$ de agua residual se midió el oxígeno disuelto mediante el equipo Oxímetro HANNA y su resultado fue $6.87 \mathrm{ppm}$.

c) La turbidez se examinó con la ayuda del equipo Turbidimetro HANNA, y la participación de un vaso precipitado con 100ml de agua residual, donde otorgó un resultado de 600 UNT (unidades nefelométricas de turbidez).

Para la medición del $\mathrm{pH}$ se utilizó el equipo $\mathrm{pH}$ metro HANNA, 7.8 otorgando resultados en unidades de $\mathrm{pH}$.

\section{Tanque séptico}

- La excavación se realizó en un área de $0.88 \mathrm{~m}^{2}$ con una profundidad de $1.70 \mathrm{~m}$.

- Para la construcción de las paredes y las cámaras se utilizaron ladrillos y mezcla de cemento y arena fina, además para la conexión de las tuberías provenientes de la cocina y servicios, se utilizaron tuberías de 2" y 4 " de diámetro y de distancia de $11 \mathrm{~m}$ y $9 \mathrm{~m}$.

- Para los efluentes de la cocina y lavandería e utilizaron tuberías de 2" y para el efluente del baño se utilizó de 4". 
- El tanque se recubrió con una capa de plástico y una plancha de tecnopor (1.05x0.75), como medida de seguridad se elaboró una tapa de madera.

\section{RESULTADOS}

Se implementó el tanque séptico y se efectuó el tratamiento del agua. Para evidenciar su eficiencia se realizó en análisis pre y pos de la calidad del agua. A continuación se muestras los principales resultados.

Los resultados sobre el número de coliformes totales y fecales tanto en las aguas pre y pos tratadas fueron superiores en contraste a los Estándares de Calidad del Ambiental definidos para el agua (ECA agua) D.S N ${ }^{\circ}$ 015-2015-MINAM en la categoría 3 (Tabla 1).

Tabla 1. Resultados del análisis fisicoquímicos y microbiológico de pre y pos tratamiento del tanque séptico y D.S N 015-2015-TR. categoria 3

\begin{tabular}{llcccc}
\hline \multicolumn{1}{c}{ Parámetro } & \multicolumn{1}{c}{ Unidad } & Pre & Post $\begin{array}{c}\text { D1: Riego de } \\
\text { cultivos de } \\
\text { tallo alto y } \\
\text { bajo }\end{array}$ & $\begin{array}{c}\% \text { de } \\
\text { Eficiencia }\end{array}$ \\
\hline Microbiológicos & & & & & \\
\hline Coliformes fecales & $\mathrm{NMP} / 100 \mathrm{ml}$ & $16 \times 10^{4}$ & $16 \times 10^{4}$ & $*$ & 100 \\
Coliformes totales & $\mathrm{NMP} / 100 \mathrm{ml}$ & $16 \times 10^{4}$ & $16 \times 10^{4}$ & 1000 & 100 \\
\hline Parámetros Físicos & & & & & \\
\hline Ph & & 7.1 & 6.6 & $6.5-8.5$ & 92.96 \\
Turbiedad & $\mathrm{NTU}$ & 228 & 204 & & 89.47 \\
Conductividad & $\mu \mathrm{S} / \mathrm{cm}$ & 2560 & 1840 & 2500 & 71.88 \\
Temperatura & ${ }^{\circ} \mathrm{C}$ & 24.8 & 24.0 & $\Delta 3$ & \\
Oxígeno Disuelto & $\mathrm{Ppm}$ & 2.07 & 1.82 & 4 & 0.88 \\
Solidos suspendidos & $\mathrm{ml} / \mathrm{L}$ & 1270 & 920 & $*$ & 72.44 \\
DBO & $\mathrm{mg} / \mathrm{L}$ & 32 & 14.4 & 15 & 50 \\
DQO & $\mathrm{mg} / \mathrm{L}$ & 70.4 & 35.2 & 40 & 45 \\
Fosfatos & $\mathrm{mg} / \mathrm{L}$ & 2.7 & 0.91 & $*$ & 33.7 \\
Oxido de fosfato & $\mathrm{mg} / \mathrm{L}$ & 4.04 & 1.36 & $*$ & 33.7 \\
Fosforo & $\mathrm{mg} / \mathrm{L}$ & 0.88 & 0.30 & $*$ & 33.7 \\
\hline Total de eficiencia & & & & & 63.12 \\
\hline
\end{tabular}

Los parámetros de organolépticos evidenciaron similitud entre los parámetros de olor y sabor en el pre y pos-tratamiento. El color varió, debido a que se encontró más materia orgánica que en la salida (Tabla 2).

Tabla 2. Resultados del análisis organolépticos de pre y pos tratamiento

del tanque séptico

\begin{tabular}{lll}
\hline Parámetro & Pretratamiento & Postratamiento \\
\hline Olor & Olor a sulfuro fuerte. & Olor a sulfuro fuerte. \\
Sabor & No aceptable & No aceptable \\
Color & Amarillo verdoso con presencia de & Amarillo verdoso pálido \\
\hline
\end{tabular}


El pH inicial fue 7.1 se tuvo un post de 6.6. Por otro lado el ECA agua indica un rango de 6.5 - 8.5 en la categoría tres D1 para la bebida de animales y riego de las plantas. Por lo cual el pH obtenido está dentro de este rango. Para el tratamiento anaeróbico oscila de 6.6 y 7.1 y el valor óptimo para la digestión anaerobia es 7.

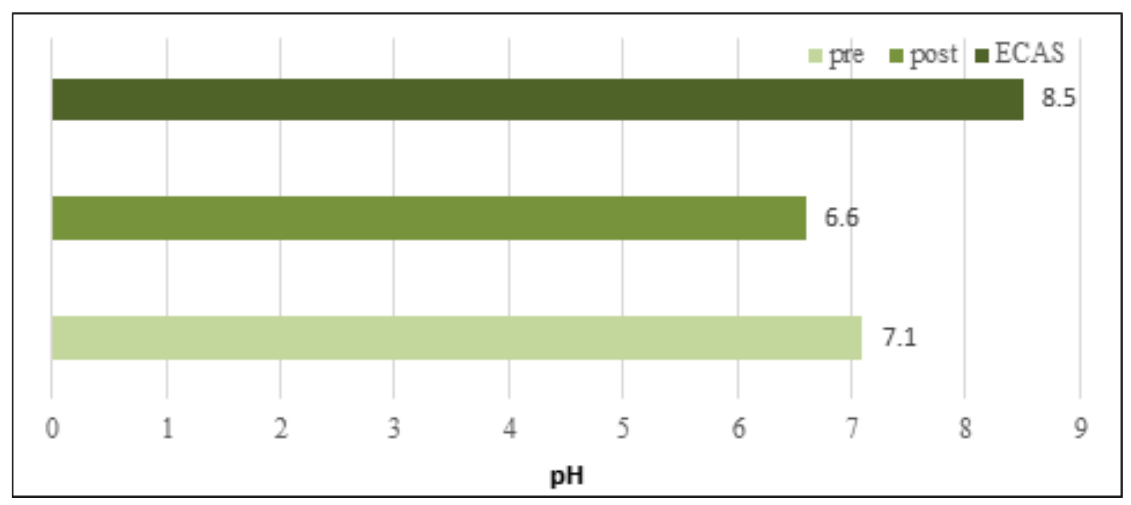

Figura 2. Análisis pre y pos tratamiento del $\mathrm{pH}$ del agua comparado con el ECA agua

La concentración de solidos suspendidos en el agua pre-tratada fue $1270 \mathrm{mg} / \mathrm{L}$, mientras que en el agua analizada después del tratamiento fue $920 \mathrm{mg} / \mathrm{L}$, se observó una mejora de la variable gracias a la acción la cámara séptica (Figura 3).

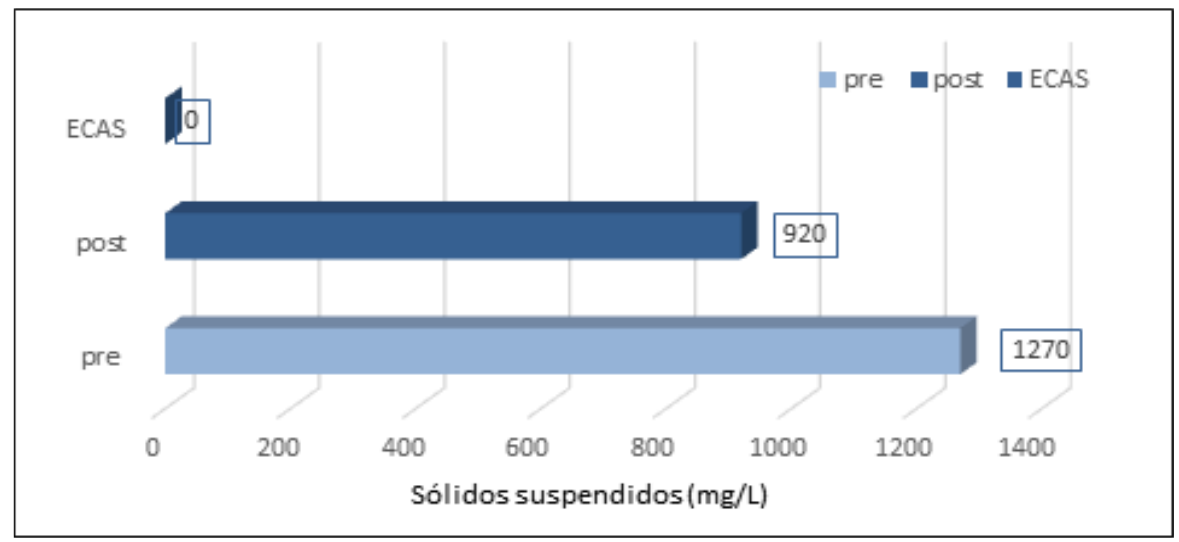

Figura 3. Análisis pre y pos tratamiento del pH del agua comparado con el ECA agua

La turbidez inicial fue 228 UNT, el proceso la sedimentación del tanque séptico mejoró este parámetro dado a que se redujo a 204 de UNT (Figura 4). 


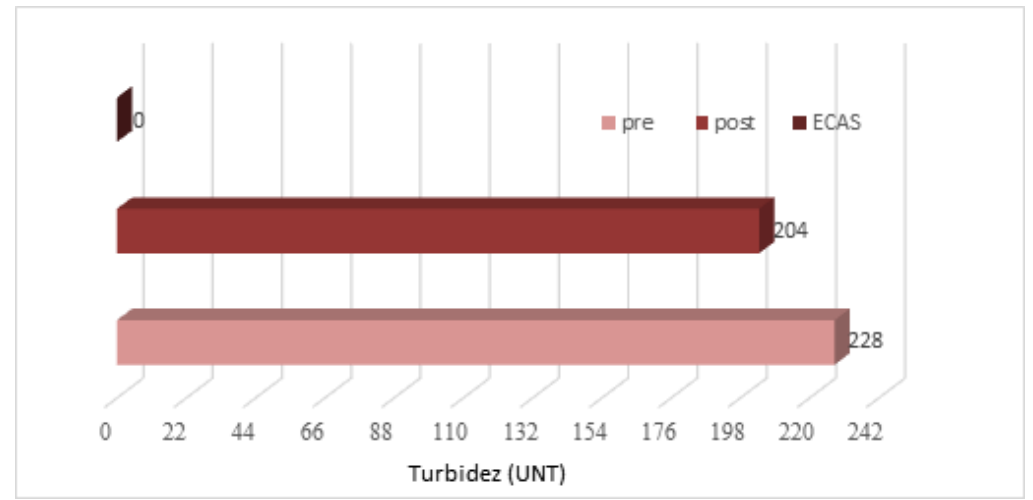

Figura 4. Análisis pre y pos tratamiento de la turbidez (UNT) del agua comparada con el ECA agua

La concentración de fosfatos en el agua pre-tratada fue de $2.7 \mathrm{mg} / \mathrm{L}$ y con el proceso se redujo a $0.91 \mathrm{mg} / \mathrm{L}$ (Figura 5). El resulta evidencia la eficiencia del sistema de tratamiento.

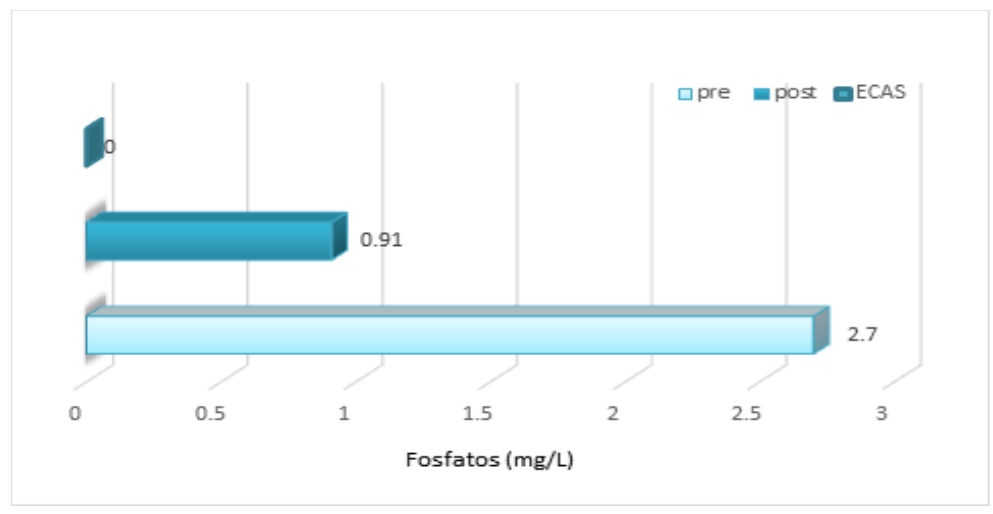

Figura 5. Análisis pre y pos tratamiento de la concentración de fosfatos (mg/L) del agua comparada con el ECA agua

La concentración de fósforo en el agua pre-tratada fue de $0.88 \mathrm{mg} / \mathrm{L}$ y el agua pos-tratada tuvo un valor de $0.3 \mathrm{mg} / \mathrm{L}$ (Figura 6), lo que permite evidenciar que el sistema fue efectivo.

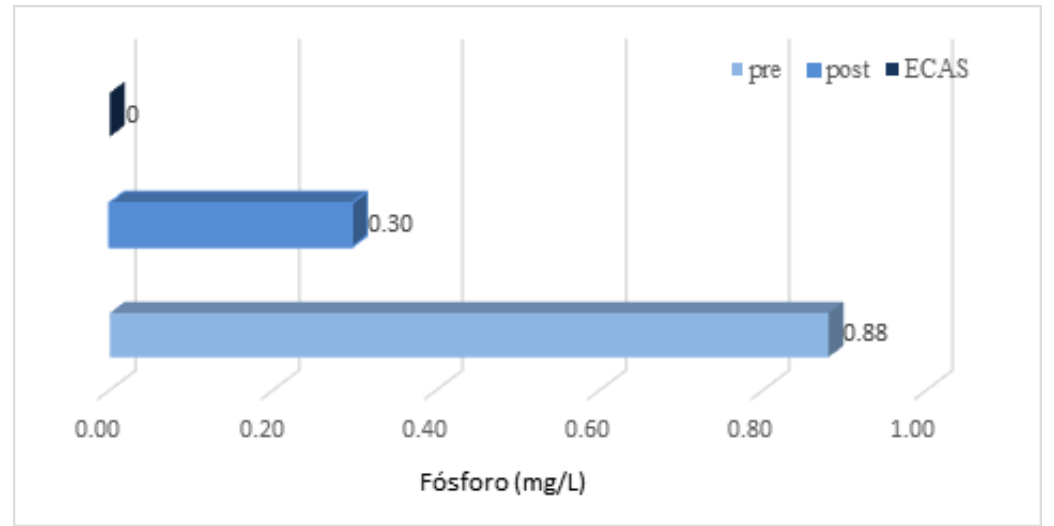

Figura 6. Análisis pre y pos tratamiento de la concentración de fósforo (mg/L) del agua comparada con el ECA agua 
La concentración de óxido de fosfato en el agua pre-tratada fue $4.04 \mathrm{mg} / \mathrm{L}$ y posterior al tratamiento la concentración disminuyó a $1.36 \mathrm{mg} / \mathrm{L}$ (Figura 7), lo que evidencia la eficiencia del sistema.

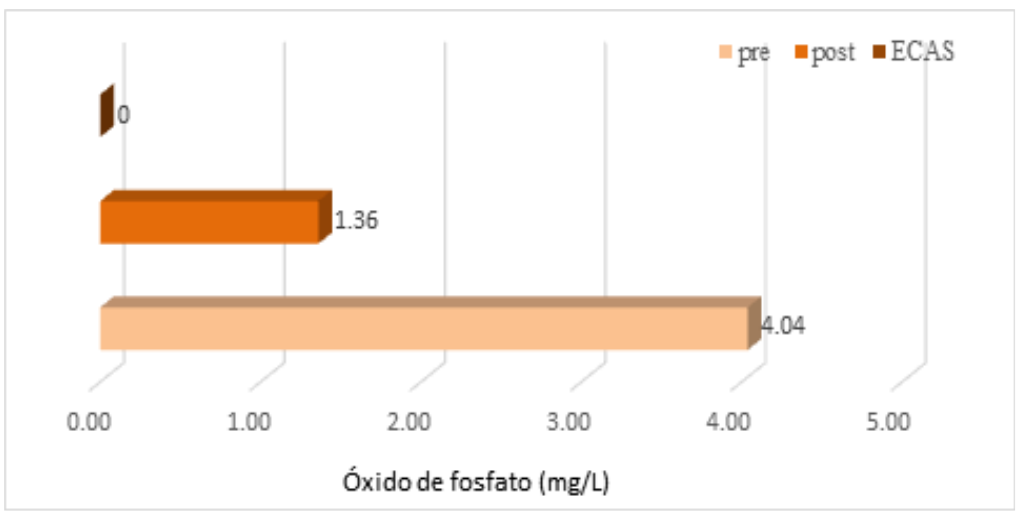

Figura 7. Análisis pre y pos tratamiento de la concentración del óxido de fósforo (mg/L) del agua comparada con el ECA agua

El DQO evidenció una clara mejora en el agua postratada puesto que disminuyo de 70.4 a $35.2 \mathrm{mg} / \mathrm{L}$, valor que se encuentra dentro del ECA agua. La eficiencia fue de $50 \%$.

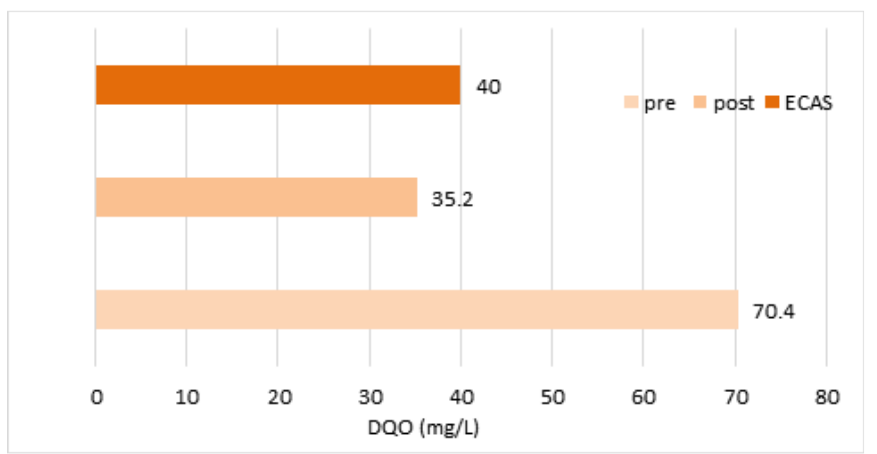

Figura 8. Análisis pre y pos tratamiento de la $\mathrm{DBO}_{5}(\mathrm{mg} / \mathrm{L})$ del agua comparada con el ECA agua

$\mathrm{La} \mathrm{DBO}_{5}$ en la fase de pretratamiento tuvo un valor de $32 \mathrm{mg} / \mathrm{L}$ y luego del tratamiento disminuyó a $14.4 \mathrm{mg} / \mathrm{L}$ (Figura 8), evidencia que el tratamiento fue exitoso, puesto que el valor final está dentro lo aceptable según el ECA agua, siendo eficiente en $45 \%$.

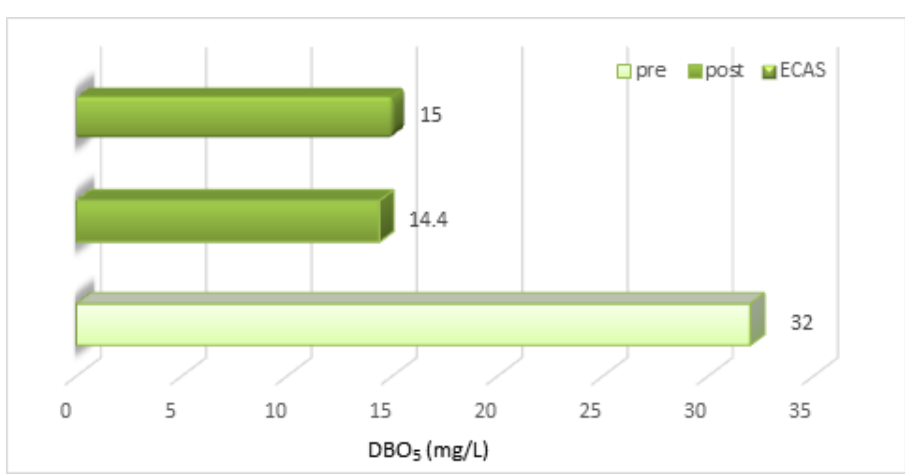

Figura 8. Análisis pre y pos tratamiento de la concentración del óxido de fósforo (mg/L) del agua comparada con el ECA agua 


\section{DISCUSIONES}

EL oxígeno disuelto es la cantidad de oxígeno que puede tener el agua a una temperatura determinada y esencial para la mayoría de los organismos vivos, dada su dependencia del proceso de respiración aeróbica para la generación de energía y para la movilización del carbono en la célula (UPRM, 2007). Por otro lado, existe una gran variedad de microorganismos (bacterias, hongos y protozoarios) para los cuales el oxígeno no es indispensable (anaerobios facultativos), para algunos el oxígeno resulta ser tóxico o inhibitorio para el crecimiento (anaerobios estrictos).

El oxígeno disuelto $1.82 \mathrm{mg} / \mathrm{L}$ que tiene el agua que hemos tratado es debido a que es un tratamiento anaerobio con bacterias facultativas y estrictas por ello menciono sería correcto la ausencia de oxígeno en el agua, para que las bacterias estrictas no mueran y se realice un tratamiento eficaz en la degradación de materia orgánica. Debido a que el oxígeno es bajo necesita estas aguas una aireación mediante paletas para la utilización de riego de plantas y para el consumo de animales.

El sistema de tanque séptico se considera como unidad de tratamiento primario que permite remover material en suspensión, excepto material coloidal o sustancias disueltas presentes en el agua. Así, la remoción del tratamiento primario permite quitar entre el 60 a $70 \%$ de sólidos suspendidos totales (OEFA, 2014). El tanque séptico como unidad de tratamiento primario con disposición final por infiltración, es efecto para la remoción de solidos suspendidos totales debido a que la comparamos y redujimos a un $72.4 \%$.

La demanda biológica de oxígeno $\left(\mathrm{DBO}_{5}\right)$ es la cantidad de oxígeno que necesitan los microorganismos para degradar la materia orgánica biodegradable existente en un agua residual. Se puede decir por tanto que la DBO representa la cantidad de materia orgánica biodegradable. En nuestro tratamiento primario se redujo el $45 \%$ de DBO. Debido a que este parámetro es bajo necesita estas aguas una aireación mediante paletas para la utilización de riego de plantas y para el consumo de animales.

La demanda química de oxígeno (DQO) es la cantidad de oxígeno necesaria para oxidar toda la materia orgánica y oxidable presente en un agua residual. Es por tanto una medida representativa de la contaminación orgánica de un efluente. En nuestro tratamiento primario se redujo el $50 \%$ de DQO. Debido a que este parámetro es bajo necesita una aireación mediante paletas para la utilización de riego de plantas y para el consumo de animales.

\section{Agradecimientos}

Al Laboratorio de Ciencias Biológicas de la Universidad Peruana Unión por otorgar facilidades logísticas para el desarrollo de esta investigación.

\section{Referencias}

Astavisa. (2015). Astavisa. Retrieved January 1, 2015, from http://www.astavisa.es/interior.asp?TR=A\&IDR=1\&idCatP=2\&seccion=2\&pag=0

García Trisolini, E. (2008). Manual de proyectos de agua potable y saneamiento en poblaciones rurales.

Jones, Don; Yahner, J. (n.d.). How a Septic System Works Operating and Maintaining the Home Septic System. Retrieved from 
http://www.decaturin.org/Documents/SepticSystemOperationsAndMaintenance.pdf

Larios- Meoño J. F., González C., Morales Y. (2015). Las aguas residuales y sus consecuencias en el Perú. Revista de la Facultad de Ingeniería de la USIL Vol. 2, № 2. Segundo semestre 2015. pp. 09-25.

Lucho-Constantino, M., Medina-Moreno, C. A. ; Beltrán-Hernández, S. A. ;, \& ; Juárez-Cruz, R. I. (2015). Diseño de fosas sépticas rectangulares mediante el uso de la herramienta FOSEP.

Normas Tecnicas Peruanas NTP. NORMA TÉCNICA I.S. 020 TANQUES SÉPTICOS (2006).

OEFA. (2014). Fiscalización ambiental en aguas Residuales. Retrieved from https://www.oefa.gob.pe/?wpfb_dl=7827

OMS. (2015). Saneamiento.

OPS, O. P. de la S. (2005). Guía para la operación y mantenimiento de tanques sépticos, tanques imhoff y lagunas de estabilización. Bvsde.paho.org. Retrieved from http://www.bvsde.paho.org/bvsacg/guialcalde/2sas/d24/055_O\&M_tanques_sépticos_Imhoff_ lag/O\&M_tanques_sépticos_Imhoff_lagunas_estabilización.pdf

Organicacion Panamericana de la salud y Organizacion Mundial de la salud, (OPS/OMS). (2005). Especificaciónes técnicas para la construcción de tanque séptico, tanque imhoff y laguna de estabilización.

Organización Panamericana de la Salud. (2015). Guía para el diseño de tanques sépticos, tanques imhoff y lagunas de estabilización. OPS/CEPIS/05.163.

Organización Panamericana de la Salud OPS. (2005). Guía para el diseño de tanques sépticos, tanques imhoff y lagunas de estabilización.

Rodríguez J. P., García-Ubaque C. A., García-Ubaque J. C. (2016). Enfermedades transmitidas por el agua y saneamiento básico en Colombia. Rev. salud pública. 18 (5): 738-745. DOI: http://dx.doi.org/10.15446/rsap.v18n5.54869

Rodríguez, J. A. (2011). Tratamiento anaerobio de aguas residuales. Universidad El Valle, (1), 1-15. State Dept of Health - Environmental Public Health - Wastewater Management Section, W. (n.d.). Do-it-yourself septic system inspection field guide (Gravity System) Field Guide for homeowners to accompany the Do-It-Yourself Septic System Inspection 201 Course. Retrieved from http://www.doh.wa.gov/portals/1/documents/pubs/337-122.pdf

UPRM. (2007). Nutrientes y Gases : Oxigeno Disuelto. Biology Massol, 1-15.

Vogel, M. P. (2005). Explains how septic systems work, how they should be laid out, how to know when to pump the tank and why septic systems fail. Also touches on additives. MT199401 HR Revised 8/2005 Septic Tank and Drainfield Operation and Maintenance. Household Equipment. Retrieved from http://store.msuextension.org/publications/HomeHealthandFamily/MT199401HR.pdf 